\title{
Cellular Defenses against Toxoplasma gondii in Newborns
}

Christopher B. Wilson and Joel E. Haas

Departments of Pediatrics and Pathology, Children's Orthopedic

Hospital and Medical Center and University of Washington

School of Medicine, Seattle, Washington 98105

bstract. Mononuclear phagocytes, particularly macrophages $(\mathbf{M} \phi)$ that have been activated by lymphokines, are the principal defense against intracellular pathogens such as Toxoplasma gondii. To determine reasons for the newborns' susceptibility to Toxoplasma infection, we compared: $(a)$ the interaction of Toxoplasma with newborns' mononuclear phagocytes (blood monocytes and two types of newborn $\mathrm{M} \phi$, those derived from blood monocytes or from placental tissue) with adults' blood monocytes and monocyte-derived $\mathrm{M} \phi$ and $(b)$ the production of $\mathbf{M} \phi$-activating lymphokines (MAF) by Concanavalin A (ConA)-stimulated newborn and adult blood mononuclear cells (MC). Newborn and adult monocytes killed Toxoplasma with equal efficiency. Similarly, survival and replication of Toxoplasma were comparable in control newborn and adult $\mathrm{M} \phi$. Exposure to adult ConA supernatants significantly decreased the survival and replication of Toxoplasma both in adult and newborn $\mathrm{M} \phi$. In contrast, exposure to cord blood ConA supernatants failed to affect the survival or the replication of Toxoplasma in newborn $\mathrm{M} \phi$ and decreased the replication but not the survival of Toxoplasma in adult $\mathbf{M} \phi$. Exposure to ConA supernatants of peripheral blood MC from 2-5-d old newborns failed to affect survival or replication of Toxoplasma in newborn or adult $\mathrm{M} \phi$. Thus, both generation of MAF by newborn blood MC and response to newborn MAF by newborn $\mathrm{M} \phi$ were impaired.

Generation of MAF by adult blood mononuclear cells

Portions of this work were presented at the annual meeting of the Western Society for Pediatric Research and Western Section of the American Federation for Clinical Research, Carmel, CA, February 1983.

This work was done while Dr. Wilson was a Hartford Foundation Fellow. Address all reprint requests to Dr. Wilson, Division of Infectious Disease, Children's Orthopedic Hospital and Medical Center, P.O. Box C-5371, Seattle, WA 98105.

Received for publication 8 September 1983 and in revised form 3 February 1984.

J. Clin. Invest.

(c) The American Society for Clinical Investigation, Inc.

$0021-9738 / 84 / 06 / 1606 / 11 \$ 1.00$

Volume 73, June 1984, 1606-1616 was not inhibited by cord blood MC nor was generation of MAF by cord blood MC increased by depletion of OKT8 antibody-binding cells, by depletion of adherent cells with or without addition of adult adherent cells, or by addition of indomethacin. Depletion of OKT4 antibody-binding cells abrogated the generation of MAF both by adult and cord blood MC. The activity of adult ConA supernatants was abrogated by dialysis at $\mathrm{pH} 2$ or by addition of anti- $\gamma$-interferon but not anti- $\alpha$-interferon antibody. However, the correlation between antiviral interferon activity and anti-Toxoplasma activity was weak $(r=0.40)$. Enhanced $\mathrm{M} \phi$ anti-Toxoplasma activity was not associated with detectably enhanced superoxide anion generation, nitroblue tetrazolium reduction, or phagolysosome fusion, and was not inhibited by catalase, superoxide dismutase, or mannitol. These results indicate that generation of and response to MAF is decreased in cells from human newborns and that $\gamma$-interferon may be the major MAF under these conditions.

\section{Introduction}

The human fetus and newborn are unusually susceptible to severe infection with a variety of microorganisms. One such pathogen is Toxoplasma gondii, which is an obligate intracellular parasite. Intrauterine Toxoplasma infection occurs as a result of transplacental transmission of parasites from mother to fetus and occurs most frequently in the third trimester $(1,2)$. The placenta may act as a barrier to transmission of infection in those cases in which active maternal infection is not associated with fetal infection $(1,2)$.

Mononuclear phagocytes, particularly activated macrophages $(\mathrm{M} \phi)^{1}$, are the principal defense against Toxoplasma infection

1. Abbreviations used in this paper: ConA, concanavalin A; ConA sups, ConA-stimulated blood mononuclear cell supernatants. FCS, fetal calf serum; FH, Ficoll Hypaque; IF, interferon; LDCF, lymphocyte-derived chemotactic factor; MAF, macrophage-activating lymphokines; MC, mononuclear cells; M $\phi$, macrophage; NBT, nitroblue tetrazolium; NK, natural killer; PHA, phytohemagglutinin; PMA, phorbol myristate acetate; RPMI + AS, RPMI 1640 plus 20-25\% human autologous or type AB serum; RPMI + FCS, RPMI + $10 \%$ fetal calf serum; SOD, superoxide dismutase. 
$(1,3,4) . M \phi$ antimicrobial function and $\mathrm{M} \phi$ activation are less efficient in newborn rodents than in adults, and this is associated with increased susceptibility to severe Toxoplasma infection (1). Little information exists regarding host defense mechanisms against intracellular pathogens in human newborns. This report describes in vitro studies of cellular defenses against Toxoplasma in the human newborn and placenta (which is a fetal organ). We observed decreased generation of and response to $M \phi$-activating lymphokines (MAF) with newborns' cells compared with adults' cells.

\section{Methods}

\section{Reagents}

Reagents were obtained from Sigma Chemical Co., St. Louis, MO, unless otherwise indicated. Hanks' balanced salt solution (HBSS), RPMI 1640, calf serum, L-glutamine, penicillin, and streptomycin were obtained from Grand Island Biological Co., Grand Island, NY. When analyzed by limulus amebocyte lysate assay (Pyrotell Associates of Cape Cod, Inc., Woods Hole, MA), the RPMI 1640 contained $<0.07-0.10 \mathrm{ng} / \mathrm{ml}$ of reference $E$. coli endotoxin. Hepes buffer was obtained from Calbiochem-Behring Corp., La Jolla, CA. Fetal calf serum (FCS) was obtained from Sterile Systems, Inc., Logan, UT; FCS contained 0.07-0.13 ng/ $\mathrm{ml}$ endotoxin and lacked detectable $(<1: 4)$ Toxoplasma antibody in the Sabin Feldman dye test. Ficoll Hypaque (FH) and Percoll were obtained from Pharmacia Fine Chemicals, Piscataway, NJ. $\left[{ }^{14} \mathrm{C}\right]$ leucine $(348 \mathrm{mCi} /$ $\mathrm{mmol}),\left[{ }^{3} \mathrm{H}\right]$ uracil $(40 \mathrm{mCi} / \mathrm{mmol})$, Omnifluor, and Aquasol 2 were obtained from New England Nuclear, Boston, MA. PhytohemagglutininP (PHA) was obtained fromm Difco Laboratories, Inc., Detroit, MI. Glutaraldehyde was obtained from Ted Pella, Inc., Irvine, CA. Diff Quik was obtained from Dade Diagnostics, Aguado, PR. Thorium oxide (Thoria-Sol) was obtained from Polysciences, Inc., Warrington, PA. OKT4 and OKT8 monoclonal antibodies were obtained from Ortho Diagnostics, Raritan, NJ. Rabbit complement was obtained from PelFreez Biologicals, Rogers, AR. Sheep antiserum to human $\alpha$-interferon (IF) (G026-502-568) and its control serum were obtained from the $\mathrm{Na}$ tional Institutes of Health, Bethesda, MD. Rabbit antiserum to human $\gamma$-IF was a generous gift from Dr. M. Langford, University of Texas, Galveston, TX (5). Human $\alpha$-IF standard (69-19) was obtained from the National Institutes of Health, Bethesda, MD. All glassware was treated at $180^{\circ} \mathrm{C}$ for $3 \mathrm{~h}$ to inactivate endotoxin.

\section{Cell preparations}

Blood mononuclear cells. Blood was obtained from healthy adult donors that lacked detectable Toxoplasma antibodies in the Sabin Feldman dye test or indirect fluorescent antibody test. Blood was obtained from the umbilical cord immediately following the delivery of healthy term newborns. In certain experiments, peripheral venous blood was obtained from healthy 2-5-d old newborns. These studies were approved by the Institutional Review Board for Human Subjects of the Children's Orthopedic Hospital and the University of Washington. Blood was anticoagulated with $0.1 \%$ potassium EDTA. Mononuclear cells (MC) were obtained by centrifugation on FH as previously described (6), washed twice in HBSS without $\mathrm{Ca}^{++}$and $\mathrm{Mg}^{++}$, and resuspended in RPMI1640 medium containing $2 \mathrm{mM}$ 1-glutamine, $10 \mathrm{mM}$ Hepes buffer, 100 $\mathrm{U} / \mathrm{ml}$ penicillin $\mathrm{G}, 100 \mu \mathrm{g} / \mathrm{ml}$ streptomycin (RPMI), and $20-25 \%$ autologous serum or human type AB serum (RPMI + AS) that lacked detectable Toxoplasma antibodies. Cells were enumerated in a hemacytometer and the percentage monocytes was determined by phagocytosis of neutral red particles (7) and by staining for nonspecific esterase (8). Cell viability was determined by trypan blue dye exclusion.

Monocyte and monocyte-derived M $\phi$ monolayers. Blood MC were adjusted to a concentration of $1 \times 10^{6}$ monocytes per $\mathrm{ml}$ in RPMI + AS. Monolayers were established in 16-mm wells of Linbro trays (Linbro Chemical Co., Hamden, CT) as previously described (9); in experiments where monolayers were examined microscopically, these wells contained $15-\mathrm{mm}$ diameter glass coverslips. Monocyte monolayers were infected within $1 \mathrm{~h}$ after cells were added to wells. $\mathbf{M} \phi$ were derived by culturing monocytes in vitro for 7-8 $d$ (9). Such monolayers were routinely $>95 \% \mathrm{M} \phi$ as determined by staining for nonspecific esterase. Monolayer cell numbers were determined as previously described $(10$, 11) by examining stained coverslips using a calibrated ocular grid.

Placental mononuclear phagocytes. Human placentas from pregnancies of 34-42-wk duration were obtained following uncomplicated vaginal and Caesarian section deliveries. After blood was aspirated from the umbilical vein, the tissue was minced, washed, finely minced, and digested in RPMI 1640 containing 150 units/ml collagenase, 60 units/ $\mathrm{ml}$ DNAase, and $2 \%$ calf serum as previously described (11). Cell preparations were enriched for $\mathbf{M} \phi$ by sequential density gradient separation over FH and Percoll, washed twice in HBSS, resuspended in RPMI $+10 \%$ FCS (RPMI + FCS), and enumerated in a hemacytometer. Approximately $0.5-0.75 \times 10^{6} \mathrm{M} \phi$ were added to $16-\mathrm{mm}$ Linbro wells, allowed to adhere for $2 \mathrm{~h}$, washed six times with HBSS, and freed of contaminating trophoblastic cells by exposure to $0.1 \%$ trypsin for 5-7 min followed by washing six times with HBSS as previously described (11). Such monolayers routinely contain $>90-95 \% \mathrm{M} \phi$; $>80 \%$ are mature $\mathbf{M} \phi$ as indicated by the absence of detectable peroxidase by ultrastructural cytochemistry. In certain experiments, placental $\mathbf{M} \phi$ were cultured in RPMI + AS with comparable results.

\section{Fibroblast monolayers and WISH cells}

Human fetal fibroblasts and WISH cells (obtained from Dr. J. Overall, University of Utah) were maintained and cultured as previously described (10).

\section{Organisms and zymosan}

Tachyzoites of the RH strain of $T$. gondii were maintained and processed as previously described (9).

Zymosan was washed three times in phosphate-buffered saline (PBS, pH 7.4) before use, opsonized by incubation for $30 \mathrm{~min}$ at $37^{\circ} \mathrm{C}$ in human serum, washed three times in PBS, and resuspended in KrebsRinger phosphate buffer, pH 7.4, containing $5.5 \mathrm{mM}$ glucose.

\section{Lymphokines}

Adult and cord blood MC were resuspended in RPMI + AS at a concentration of $5.0 \times 10^{6}$ cells $/ \mathrm{ml}$. $2.5 \mathrm{ml}$ were added to $15-\mathrm{ml}$ conical tubes (Falcon Plastics, Oxnard, CA). $250 \mu$ l of Concanavalin A (ConA) or PHA in the indicated concentrations or medium alone (control) were added, and tubes were incubated at $37^{\circ} \mathrm{C}$ for the indicated intervals. At that time, an equivalent concentration of ConA or PHA was added to control tubes and all tubes were then centrifuged at $250 \mathrm{~g}$ for 10 min. Supernatants were aspirated and those containing ConA were added to $400 \mathrm{mg}$ of Sephadex G-10 for $1 \mathrm{~h}$ to adsorb the ConA (12). The Sephadex was then removed by centrifugation at $250 \mathrm{~g}$ for $10 \mathrm{~min}$, supernatants were aspirated, sterilized by filtration $(0.2 \mu \mathrm{m}$ Millex filters, Millipore Corp., Boston, MA), and stored at $4^{\circ} \mathrm{C}$. Activity in our assays was retained for up to 1 mo under these conditions. Lymphocyte culture supernatants were added to monolayers at the times and concentrations indicated in Results. Lymphocyte transformation for each cell preparation in response to the same stimuli was assessed as previously described (6). 
In certain experiments, blood MC were depleted of adherent cells by adherence to plastic Petri dishes (Corning Glass Co., Corning, NY) as previously described (6). Nonadherent cells were then added to nylon wool columns and incubated for $1 \mathrm{~h}$; nonadherent cells were collected as described (13), washed once in HBSS, and resuspended in RPMI + AS. In other experiments, MC were suspended at a concentration of $1 \times 10^{7} / \mathrm{ml}$ in RPMI + FCS and incubated for $45 \mathrm{~min}$ with OKT4 or OKT8 antibody (1:200 final dilution). Then, rabbit serum which had been stored at $-70^{\circ} \mathrm{C}$ was added (1:6 final dilution) as a source of complement, and the cells were incubated for $45 \mathrm{~min}$ at $37^{\circ} \mathrm{C}$. The cell suspensions were then centrifuged over $\mathrm{FH}$ to remove nonviable cells, washed twice in HBSS, and resuspended in RPMI + AS. Such preparations contained $<2 \%$ OKT 4 or OKT 8 antibody-containing cells, respectively, as determined by indirect immunofluorescent staining with fluoresceinated $\left(\mathrm{Fab}_{2}^{\prime}\right)$ goat antimouse immunoglobulin. Adherent celldepleted cell preparations, and OKT4 and OKT8-depleted cell preparations were then resuspended at a concentration of $5 \times 10^{6}$ viable cells/ $\mathrm{ml}$ and stimulated with ConA to generate lymphocyte culture supernatants as described above.

In certain experiments, lymphocyte culture supernatants were dialyzed against pH 2 glycine buffer or PBS for $24 \mathrm{~h}$, then dialyzed for $12 \mathrm{~h}$ against PBS, and $12 \mathrm{~h}$ against RPMI before use. In other experiments, sufficient antihuman $\alpha$ - or $\gamma$-IF antibody to neutralize 3500 units of activity $/ \mathrm{ml}$ was added to supernatants and incubated for $30 \mathrm{~min}$ at $37^{\circ} \mathrm{C}$ before use.

\section{$M \phi$ interaction with Toxoplasma}

Monolayers were cultured as indicated in Results, washed six times with HBSS, and then $1 \times 10^{6}$ Toxoplasma in $0.5 \mathrm{ml} \mathrm{RPMI}+$ FCS were added to each. After $1 \mathrm{~h}$ at $37^{\circ} \mathrm{C}$ in $5 \% \mathrm{CO}_{2}: 95 \%$ air, monolayers were washed eight times with HBSS to remove extracellular organisms. Immediately or after reincubation for $20 \mathrm{~h}$ in fresh medium, monolayers were fixed in $2.5 \%$ glutaraldehyde in $0.1 \mathrm{M} \mathrm{Na}$ cacodylate buffer $(\mathrm{pH}$ 7.0), stained with Diff Quik, and examined microscopically in a blinded manner as previously described $(9,10)$.

Intracellular survival and replication of organisms was also assessed by monolayer incorporation of $\left[{ }^{3} \mathrm{H}\right]$ uracil by using a modification of previously described methods $(14,15)$. Wells without coverslips were infected for $1 \mathrm{~h}$ as described above, washed, and $1 \mathrm{ml}$ of fresh medium and $10 \mu \mathrm{Ci}$ of $\left[{ }^{3} \mathrm{H}\right]$ uracil were added to each. After incubation for 18 $\mathrm{h}$, monolayers were washed eight times with HBSS and solubilized in $0.1 \%$ Triton $\mathrm{X}-100$. An aliquot was saved for determination of protein content by a modification of the Lowry method (16) using bovine serum albumin as the standard; $10 \%$ ice-cold TCA was added to the remainder and the precipitate was collected on filter papers, dried, added to vials containing Omnifluor, and the associated radioactivity determined in a liquid scintillation spectrometer.

\section{Effects of inhibitors}

The oxygen metabolite scavengers superoxide $\left(\mathrm{O}_{\overline{2}}\right)$ dismutase (SOD, 2.5 $\mathrm{mg} / \mathrm{ml}, 2,800 \mathrm{U} / \mathrm{mg}$ protein), catalase $(0.25 \mathrm{mg} / \mathrm{ml}, 34,000 \mathrm{U} / \mathrm{mg}$ protein), and mannitol ( $50 \mathrm{mM}$ ) were added to monolayers for $4 \mathrm{~h}$ before and during the assays where indicated.

\section{$O_{\overline{2}}^{\overline{2}}$ generation and nitroblue tetrazolium $(N B T)$ reduction}

$\mathrm{O}_{\overline{2}}$ release by $\mathrm{M} \phi$ monolayers was assessed in response to optimal concentrations of phorbol myristate acetate (PMA, $1.6 \mu \mathrm{g} / \mathrm{ml}$ ) or opsonized zymosan $(2.5 \mathrm{mg} / \mathrm{ml})$ by SOD-inhibitable reduction of ferricytochrome $C$ as previously described (17), except that monolayers were in 16-mm rather than 35-mm wells. NBT reduction by $\mathbf{M} \phi$-phagocytosing Toxoplasma was assessed microscopically as previously described (9).

\section{Phagolysosome fusion}

$\mathrm{M} \phi$ were cultured in 60 -mm Petri dishes (Corning Glass Works) and lysosomes were labeled with thorium oxide $24 \mathrm{~h}$ before the assay as described by Goren et al. (18). M $\phi$ monolayers were then washed and infected with Toxoplasma for $1 \mathrm{~h}$ as described above. One set of dishes was immediately fixed in $2.5 \%$ glutaraldehyde in Na-cacodylate buffer; another set was incubated for an additional $1-2 \mathrm{~h}$ and then fixed. Dishes were washed, processed, and examined by transmission electron microscopy as previously described (11). Results with monolayers that were processed 1 or $2 \mathrm{~h}$ after infection were comparable and they were pooled.

\section{Interferon assays}

The IF content of lymphocyte culture supernatants was assayed by a previously described plaque reduction assay using vesicular stomatitis virus and human foreskin fibroblasts (19). A standard preparation of human $\alpha$-IF was used in each assay for comparison.

\section{Statistics}

The significance of the differences between means was evaluated by two-tailed Student's $t$ test or by paired $t$ test as appropriate. The significance of differences between nonparametric data was examined by Fisher's exact test or by the chi-square test for small and large samples, respectively (20).

\section{Results}

Interaction of Toxoplasma with blood monocytes. During the 1-h infection period, comparable numbers of freshly isolated blood monocytes from adults and newborns phagocytosed Toxoplasma (Fig. 1); the mean numbers of intracellular Toxoplasma per infected cell were also comparable (not shown). Toxoplasma were cleared at a similar rate by both. Examination of cytocentrifuge-prepared slides of the supernatants (15) indicated that the decrease in the percentage of infected cells was not due to a selective loss of infected cells from the monolayers. Toxoplasma replicated poorly in both types of monocytes (Fig.

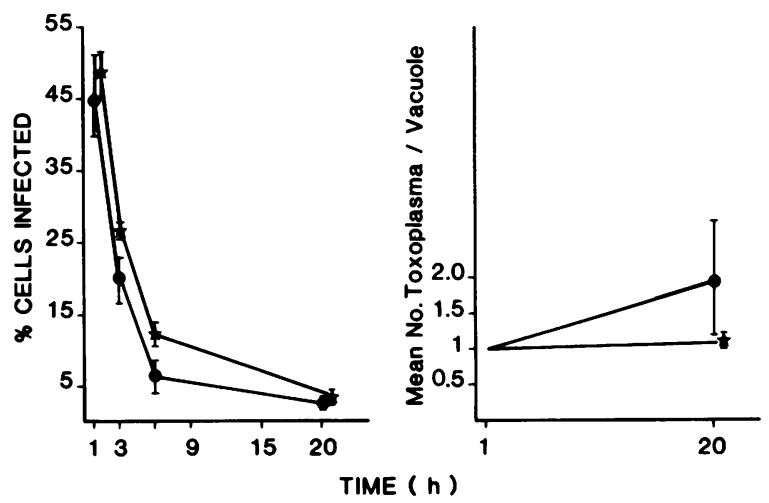

Figure 1. Interaction of Toxoplasma with freshly isolated monocytes. Adult (๑) and cord blood (*) monocytes were infected with Toxoplasma tachyzoites, and at $1 \mathrm{~h}$, extracellular organisms were removed and the infected monolayers were incubated for the indicated intervals. The percentage of infected monocytes and mean no. of Toxoplasma per vacuole were determined by light microscopy of Diff Quik stained smears. Results are the mean \pm SE of four experiments. 
1); the mean number of parasites per vacuole at $20 \mathrm{~h}$ in adults' and newborns' monocytes was not significantly different.

Interaction of Toxoplasma with freshly isolated placental macrophages. When placental macrophages were infected immediately or within $16 \mathrm{~h}$ of isolation, survival and replication of Toxoplasma were greater than in freshly isolated blood monocytes but comparable with that in $\mathbf{M} \phi$ derived from adult blood monocytes that had been cultured in vitro for 4-5 d (Fig. 2). Exposure of adult monocyte-derived $\mathbf{M} \phi$ to collagenase and trypsin under conditions used to isolate placental $\mathbf{M} \phi$ did not affect uptake, survival, or replication of Toxoplasma in these cells (not shown). If placental $\mathbf{M} \phi$ and adult monocyte-derived $\mathbf{M} \phi$ were cultured in vitro for a longer period of time (7-9 d), phagocytosis $(P<0.001$ and $<0.02$, respectively) and intracellular replication $(P<0.001)$ of Toxoplasma increased significantly in both (Fig. 2).

Conditions for enhancement of $M \phi$ anti-Toxoplasma activity by blood MC culture supernatants. Supernatants from mitogen or antigen-stimulated adult lymphocyte cultures have been reported to enhance the anti-Toxoplasma activity of human monocyte-derived $\mathbf{M} \phi(21,22)$. Under our conditions, ConAstimulated adult blood MC culture supernatants (ConA sups) did not consistently enhance the anti-Toxoplasma activity of adult $\mathbf{M} \phi$ derived from monocytes that had been cultured in vitro for $<96 \mathrm{~h}$ before they were exposed to supernatants for
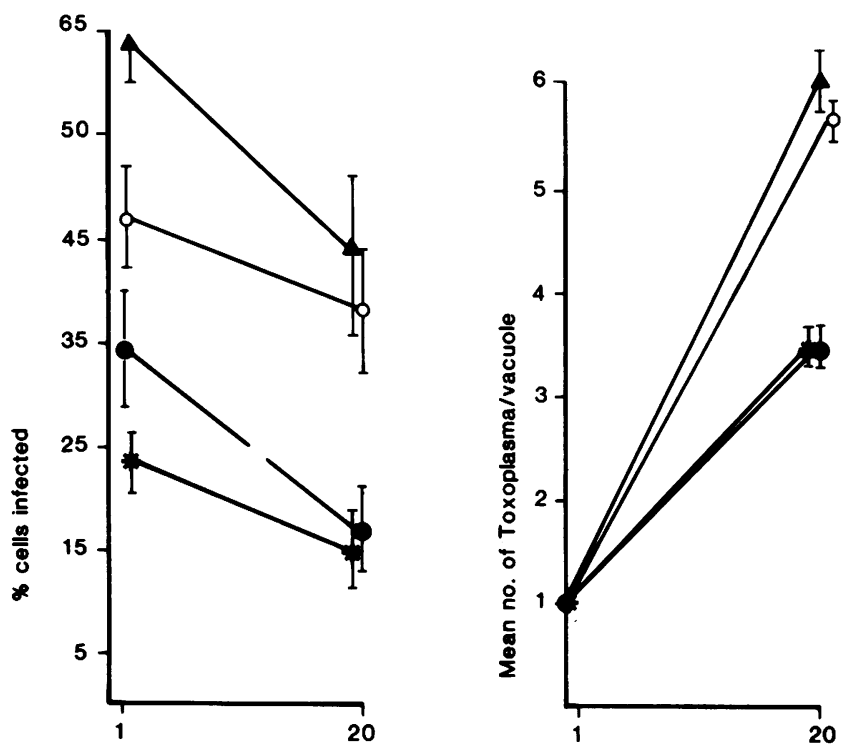

Figure 2. Interaction of Toxoplasma with adult $\mathrm{M} \phi$ derived from the culture of blood monocytes in vitro for 4-5 d (•) or 7-9 $d(0)$ and freshly isolated placental $\mathbf{M} \phi(*)$ or placental $\mathbf{M} \phi$ cultured in vitro for 7-9 $d(\Delta) . M \phi$ were infected and assessed as described for Fig. 1 . Results are the mean \pm SE of 8 (adult $M \phi$ ) or 10 (placental $M \phi$ ) experiments. After the $1-\mathrm{h}$ infection period, the mean number of Toxoplasma per infected $\mathrm{M} \phi$ was $1.6 \pm 0.1,1.8 \pm 0.1,1.2 \pm 0.1$, and $2.1 \pm 0.4$ for 4-5-d and 7-9-d adult $M \phi$ and freshly isolated and 7-9-d placental $\mathbf{M} \phi$, respectively.
48-72 $\mathrm{h}$; unexposed control $\mathrm{M} \phi$ and $\mathrm{M} \phi$ exposed to the adult ConA sups both cleared $\sim 50 \%$ of Toxoplasma between 1 and $20 \mathrm{~h}$, and the mean number of Toxoplasma per vacuole was $3.5 \pm 0.2$ and $3.4 \pm 0.4$, respectively. However, adult monocytes that had been cultured in vitro for $>96 \mathrm{~h}$ before addition of supernatants, developed enhanced anti-Toxoplasma activity when exposed to adult ConA sups (Fig. 3). Enhancement of placental $\mathbf{M} \phi$ anti-Toxoplasma activity also occurred only when cells were cultured in vitro for $>72 \mathrm{~h}$ before exposure to adult ConA sups. However, this period before placental $\mathbf{M} \phi$ would respond to adult ConA sups may be due in part to the effects of the isolation procedure. $\mathbf{M} \phi$ derived from adult monocytes that had been cultured in vitro for $5 \mathrm{~d}$ and then exposed to collagenase and trypsin under conditions used to isolate placental $\mathrm{M} \phi$ lost their ability to respond to adult ConA sups with increased anti-Toxoplasma activity for at least $72 \mathrm{~h}$. When adult monocytederived $\mathbf{M} \phi$ were exposed to adult ConA sups before treatment with collagenase and trypsin, and then infected, enhanced antiToxoplasma activity was observed (not shown). This suggests that enzyme treatment interferes with the action of adult ConA sups on $\mathbf{M} \phi$ rather than impairing $\mathrm{M} \phi$ anti-Toxoplasma activity directly.

In preliminary experiments, exposure of adult or placental $\mathbf{M} \phi$ to adult ConA sups at a final concentration of $30 \%$ (compared with 10 or $50 \%$ ) for $3 \mathrm{~d}$ (compared with 2 or $4 \mathrm{~d}$ ) resulted in the greatest enhancement of Toxoplasma clearance and the greatest inhibition of intracellular replication. Daily addition of 10-30\% adult ConA sups for $3 \mathrm{~d}$ had an effect similar to a single addition of $30 \%$ supernatants for $3 \mathrm{~d}$ before the assay. Also, the use of $40 \mu \mathrm{g} / \mathrm{ml}$ (compared with 20 or $80 \mu \mathrm{g} / \mathrm{ml}$ ) of ConA during production of adult ConA sups resulted in supernatants that optimally enhanced $\mathbf{M} \phi$ anti-Toxoplasma activity (not shown). These conditions were used for the subsequent studies unless otherwise indicated.

Effects of ConA supernatants from adults and newborns on survival and replication of Toxoplasma. Replication of Toxoplasma in adult or cord blood $\mathbf{M} \phi$ or placental $\mathbf{M} \phi$ was significantly inhibited after exposure of these cells to adult ConA sups (Fig. $3 \mathrm{~A}$ ) or to supernatants from Toxoplasma antigenstimulated blood MC from immune adults (not shown). In contrast, only in adult $\mathbf{M} \phi$ was replication of Toxoplasma significantly inhibited after exposure to cord blood ConA sups. Further, replication of Toxoplasma was significantly less in adult $\mathbf{M} \phi$ and placental $\mathbf{M} \phi$ that were exposed to adult ConA sups compared with cord blood ConA sups (Fig. $3 \mathrm{~A}$ ). Replication of Toxoplasma in adult $\mathbf{M} \phi$, cord blood $\mathbf{M} \phi$, or placental $\mathbf{M} \phi$ was not affected by exposure to unstimulated adult or cord blood MC supernatants (mean no. of Toxoplasma per vacuole, $4.9 \pm 0.4,5.2 \pm 0.6$, and $6.4 \pm 0.6$, respectively).

Exposure to adult or cord blood ConA sups did not affect the percentage of adult, cord blood, or placental $\mathbf{M} \phi$ that were infected or the number of Toxoplasma per infected cell following the $1 \mathrm{~h}$ challenge (Fig. $3 \mathrm{~B}$ ). Significantly fewer adult, cord blood, or placental $\mathrm{M} \phi$ that were exposed to adult ConA sups remained infected by $20 \mathrm{~h}$ compared with each type of untreated 

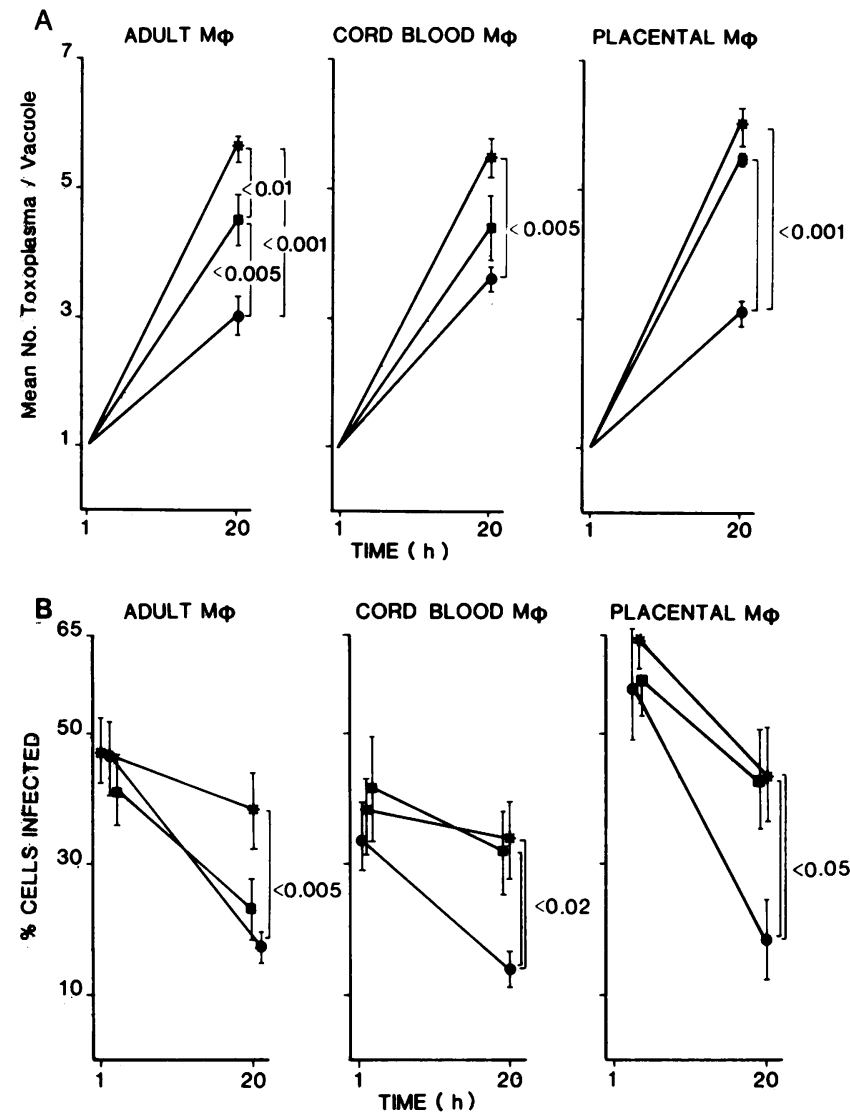

Figure 3. Effects of ConA-stimulated adult and cord blood mononuclear cell supernatants on replication $(A)$ and survival $(B)$ of Toxoplasma in adult $\mathrm{M} \phi$, cord blood $\mathrm{M} \phi$, and placental $\mathrm{M} \phi$. $\mathrm{M} \phi$ were exposed to adult ConA sups (๑), cord blood ConA sups ( $\bullet$ ), or medium alone (*). M $\phi$ were infected and assessed as described for Fig. 1. Results with $\mathbf{M} \phi$ that were exposed to unstimulated adult or cord blood sups were comparable with those with medium alone. Results are the mean $\pm S E$ of 23-24, 4-6, and 6-8 experiments, respectively. After the 1-h infection period, the mean no. of Toxoplasma per infected cell for $\mathrm{M} \phi$ exposed to medium alone, adult ConA sups, or cord blood ConA sups was $1.8 \pm 0.1,1.7 \pm 0.1$, and $1.6 \pm 0.1$ for adult $M \phi$; $2.1 \pm 0.2,2.0 \pm 0.2$, and $2.1 \pm 0.3$ for cord blood $M \phi ; 2.1 \pm 0.4,1.6 \pm 0.4$, and $2.0 \pm 0.2$ for placental $M \phi$, respectively.

M $\phi$ or to cord blood or placental M $\phi$ that were exposed to cord blood ConA sups (Fig. 3 B). In contrast, with each type of $\mathbf{M} \phi$, there was no significant difference in the percentage of infected $\mathrm{M} \phi$ at $20 \mathrm{~h}$ between controls and cells exposed to cord blood ConA sups.

It is unlikely that these differences were due to increased or selective cell loss from monolayers that were exposed to adult ConA sups. The number of each type of $\mathrm{M} \phi$ in untreated monolayers and monolayers exposed to adult or cord blood ConA sups was comparable after $1 \mathrm{~h}(1.46 \pm 0.13,1.35 \pm 0.13$, and $1.52 \pm 0.15 \times 10^{5}$, respectively) and $20 \mathrm{~h}(1.03 \pm 0.26,1.08 \pm 0.30$,
$0.94 \pm 0.18 \times 10^{5}$, respectively). Similarly, when the detached cells in 20-h culture supernatants from three to four representative experiments with adult $\mathbf{M} \phi$ were examined in cytocentrifuge-prepared slides, the percentage of infected cells and the mean no. of Toxoplasma per vacuole paralleled those of the respective monolayers; the mean percentage of infected cells was 33,12 , and 8 , and the mean no. of Toxoplasma per vacuole was 4.0, 1.6, and 2.1 in untreated and adult or cord blood ConA sups exposed $\mathbf{M} \phi$, respectively.

Similar results were obtained when survival and replication of Toxoplasma were assessed by uptake of $\left[{ }^{3} \mathrm{H}\right]$ uracil by infected $\mathbf{M} \phi$. Uptake of $\left[{ }^{3} \mathrm{H}\right]$ uracil by Toxoplasma-infected adult $\mathbf{M} \phi$ that had been exposed to adult control sups $(2215 \pm 319 \mathrm{cpm} /$ $\mu \mathrm{g}$ protein) and to cord blood ConA sups $(1999 \pm 1046 \mathrm{cpm} / \mu \mathrm{g}$ protein) were comparable, whereas uptake of $\left[{ }^{3} \mathrm{H}\right]$ uracil by infected $M \phi$ that were exposed to adult ConA sups $(1240 \pm 364$ $\mathrm{cpm} / \mu \mathrm{g}$ protein) was significantly $(P<0.025)$ less. Monolayer protein contents were comparable. Similarly, uptake of $\left[{ }^{3} \mathrm{H}\right]$ uracil by placental $\mathrm{M} \phi$ that had been exposed to adult but not to cord blood ConA sups was significantly $(P<0.05)$ less than that by $\mathbf{M} \phi$ exposed to adult control sups (not shown). $\left[{ }^{3} \mathrm{H}\right]$ uracil uptake by uninfected $\mathbf{M} \phi$ or Toxoplasma alone was $<1 \%$ of that by control-infected $\mathbf{M} \phi$.

To determine if peripheral blood MC from newborns, like cord blood MC, were deficient in production of factors that enhance $\mathbf{M} \phi$ activity against Toxoplasma, peripheral blood MC were obtained from 2-5-d old newborns and used to produce ConA sups. In three experiments each, exposure to newborn peripheral blood MC ConA sups did not decrease the survival or replication of Toxoplasma at $20 \mathrm{~h}$ in adult $\mathbf{M} \phi(39.4 \pm 2.7 \%$ infected $\mathrm{M} \phi, 5.7 \pm 0.1$ Toxoplasma/vacuole) or in placental $\mathrm{M} \phi$ (46.0 $\pm 5.2 \%$ infected $M \phi, 5.8 \pm 0.1$ Toxoplasma/vacuole) compared with control $\mathrm{M} \phi$ ( 31 and $43 \%$ infected $\mathrm{M} \phi$ and 5.5 and 4.9 Toxoplasma/vacuole, respectively).

Basis for differences between the effects of adult and cord blood ConA sups on M activation against Toxoplasma. Decreased activation of $\mathbf{M} \phi$ by cord blood ConA sups was not associated with a failure of lymphocytes to transform in response to ConA, since uptake of $\left[{ }^{3} \mathrm{H}\right]$ thymidine by ConA-stimulated cord blood MC (50107 $\pm 5864 \mathrm{cpm})$ was comparable to that by ConA-stimulated adult blood MC (54971 $\pm 6058 \mathrm{cpm})$. Uptake of $\left[{ }^{3} \mathrm{H}\right]$ thymidine by unstimulated cord blood MC $(4208 \pm 764$ $\mathrm{cpm})$ was greater than that by adult blood MC $(1079 \pm 200 \mathrm{cpm})$. Varying the concentration of cord blood ConA sups added to adult $\mathbf{M} \phi$ culture medium did not affect the results; the mean no. of Toxoplasma per vacuole was 5.6, 5.3, 5.0, and 5.4 with addition of $5,10,30$, and $50 \%$ cord blood ConA sups, respectively $(n=2-5)$. Similarly, use of 20 or $80 \mu \mathrm{g} / \mathrm{ml}$ of ConA, instead of $40 \mu \mathrm{g} / \mathrm{ml}$ of ConA, to stimulate cord blood MC did not affect results (not shown). Furthermore, supernatants of cord blood MC that were stimulated with PHA were not more effective at inducing toxoplasmastatic activity in adult $\mathbf{M} \phi$ than were ConAstimulated cells from the same subject (mean no. of Toxoplasma 
per vacuole: cord blood PHA sup $=5.4$, cord blood ConA sup = 5.1).

To determine if a subpopulation of cord blood MC accounted for this difference, we first determined the subpopulation necessary for production of MAF by adult blood MC. ConA supernatants of adult blood MC that had been treated with OKT4 antibody and complement were significantly less active than supernatants prepared under the standard conditions (conventional supernatants) both in their effects on replication (Table I) and on survival (not shown) of Toxoplasma in adult $\mathbf{M} \phi$; ConA-stimulated OKT4-depleted blood MC took up 50\% as much $\left[{ }^{3} \mathrm{H}\right]$ thymidine as did undepleted blood MC (not shown). In contrast, treatment of adult blood MC with OKT8 antibody and complement (Table I) or depletion of adherent cells ( $1 \%$ esterase-positive cells remained, not shown) were without effect. These results suggested that OKT4 antibody-binding cells were the major source of the MAF in adult ConA sups.

Similar results were observed with cord blood ConA sups; treatment of cord blood MC with OKT8 antibody and complement was without effect, whereas ConA supernatants of cells treated with OKT4 antibody and complement were even less effective $(P<0.05)$ than conventional cord blood ConA sups

Table I. Effects of Different Culture Conditions on Generation of Macrophage-Activating ConA Supernatants by Blood Mononuclear Cells

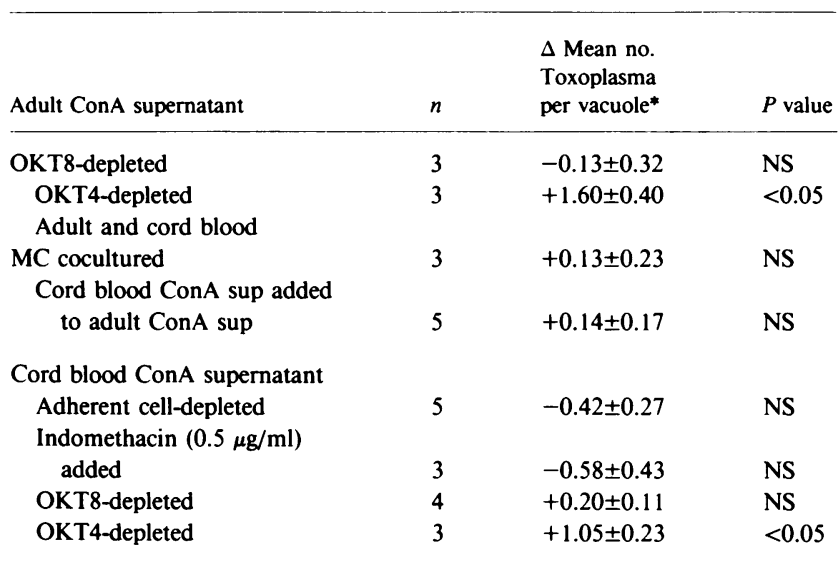

Conventional adult and cord blood ConA-stimulated sups were produced as described in Methods. Where indicated, supernatants were produced in a similar manner either by using cell preparations deleted of adherent cells or of OKT8 or OKT4 antibody-binding cells, or by using cocultures of equal numbers of adult and cord blood blood MC. Supernatants were added to adult monocytederived $\mathrm{M} \phi 72 \mathrm{~h}$ before they were infected with Toxoplasma.

* Results are the mean no. of Toxoplasma per vacuole of monolayers exposed to study supernatants minus that for monolayers exposed to the appropriate conventional supernatant. In the experiments with newborn ConA sups, the mean no. of Toxoplasma per vacuole was $5.7 \pm 0.2$ and $4.4 \pm 0.3$ in unexposed and conventional cord blood ConA sup exposed $\mathbf{M} \phi$; in the experiments with adult supernatants, the mean no. of Toxoplasma per vacuole was $5.7 \pm 0.3$ and $3.4 \pm 0.3$ in unexposed and conventional adult ConA sup exposed $\mathrm{M} \phi$.
Table II. Effects of Different Treatments on Macrophage Activation by ConA Supernatants of Adult Blood Mononuclear Cells

\begin{tabular}{llll}
\hline $\begin{array}{l}\text { Treatment of adult ConA } \\
\text { supernatants }\end{array}$ & $n$ & $\begin{array}{l}\Delta \text { Mean no. } \\
\text { Toxoplasma } \\
\text { per vacuole* }\end{array}$ & $P$ value \\
\hline Dialyzed at pH 2 & 4 & $+1.50 \pm 0.37$ & $<0.05$ \\
Dialzyed at pH 7.4 & 2 & $-0.10 \pm 0.10$ & NS \\
Treated with anti- $\gamma-$ & 3 & $+1.90 \pm 0.35$ & $<0.05$ \\
IF & 3 & $+0.30 \pm 0.42$ & NS \\
Treated with anti- $\alpha-$ IF & & &
\end{tabular}

ConA supernatants were produced as described in Methods. They were treated as indicated before use. Supernatants were added to adult monocyte derived $\mathrm{M} \phi 72 \mathrm{~h}$ before they were infected with Toxoplasma.

* Results were calculated as in Table I. The mean no. of Toxoplasma per vacuole was $5.6 \pm 0.3$ and $3.5 \pm 0.2$ in unexposed and conventional adult ConA sup exposed $\mathrm{M} \phi$.

(Table I). Because adherent cells may suppress lymphocyte responses by secretion of prostaglandin E (23), we assessed the effects of adherent cell depletion ( $1 \%$ esterase-positive cells remained) or addition of indomethacin. The activity of such supernatants was not signficantly different than that of conventional cord blood ConA sups (Table I). Addition of $10 \%$ adult adherent cells to nonadherent newborn MC was also without effect (not shown). Cord blood MC did not inhibit production of MAF when co-cultured with adult blood MC and ConA (Table I). Similarly, cord blood ConA sups did not appear to contain a soluble inhibitor of MAF (24), since the toxoplasmastatic effect of adult ConA sups was not affected by addition of cord blood ConA sups (Table I).

Results similar to these were obtained in selected experiments using placental $\mathbf{M} \phi$ instead of adult $\mathbf{M} \phi$ and cord blood ConA sups under variable conditions as described above.

Partial characterization of MAF in culture supernatants. Dialysis of adult ConA sups at pH 7.4 did not affect $\mathrm{M} \phi$ antiToxoplasma activity (Table II). In contrast, dialysis of adult ConA sups at pH 2 abrogated their ability to activate $\mathrm{M} \phi$ to inhibit Toxoplasma replication. Further, addition of antihuman $\gamma$-IF but not antihuman $\alpha$-IF abrogated the activity of adult ConA sups on replication (Table II) and on survival of Toxoplasma (not shown). Undiluted adult ConA sups contained more IF (1815 \pm 1078 units/ml, $n=4)$ than cord blood ConA sups $(760 \pm 559$ units $/ \mathrm{ml})$. However, there was substantial variability in IF content both of adult and of cord blood ConA sups, and the correlation between supernatant IF titer and its effect on inhibition of Toxoplasma replication in $\mathbf{M} \phi$ was weak $(r=0.40)$. Control supernatants or supernatants of OKT4-depleted cells contained $<100$ units/ml of IF. 
These supernatants did not induce anti-Toxoplasma activity in nonphagocytic cells, since exposure to adult ConA sups did not impede replication of Toxoplasma in human fibroblasts as indicated by uptake of $\left[{ }^{3} \mathrm{H}\right]$ uracil by infected cells (control cells $=4227 \pm 1364$ and adult ConA sup exposed cells $=4233 \pm 1481$ $\mathrm{cpm} / \mu \mathrm{g}$ protein, respectively; $n=3$ ). Similar results were obtained with WISH cells (not shown).

Mechanism of enhanced M $\phi$ antimicrobial activity. Previous studies by ourselves $(9,10)$ and by Murray and co-workers $(25-$ 28) have implicated reactive oxygen metabolites as one mediator of $\mathbf{M} \phi$ anti-Toxoplasma activity. However, exposure of adult or placental $\mathbf{M} \phi$ to adult ConA sups under the same conditions that enhanced anti-Toxoplasma activity did not increase $\mathrm{O}_{\bar{i}}$ release in response to PMA or zymosan or increase NBT reduction around ingested Toxoplasma (Table III). In contrast, freshly isolated monocytes released 2.5 to 5 times as much $\mathrm{O}_{\bar{i}}^{\bar{z}}$ as untreated or ConA sup-exposed $\mathrm{M} \phi$, and reduced NBT around ingested Toxoplasma. Further, addition of oxygen metabolite scavengers before and during the assay did not inhibit replication $(2.7 \pm 0.2,2.2 \pm 0.3,2.5 \pm 0.3$, and 2.5 Toxoplasma per vacuole in monolayers without or with catalase, mannitol, or SOD, respectively) or survival (not shown) of Toxoplasma in supernatant exposed $\mathrm{M} \phi(n=3)$. Similarly, fusion of thorium oxide-labeled lysosomes with Toxoplasma-containing phagosomes was slightly but not significantly greater in $\mathbf{M} \phi$ exposed

Table III. Effect of ConA-stimulated Adult Blood MC Supernatants on $O_{\bar{\Sigma}}^{\overline{1}}$ Production and NBT Reduction by Adult and Placental M $\phi$

\begin{tabular}{|c|c|c|c|}
\hline & \multicolumn{2}{|c|}{$\mathrm{O}_{2}^{+*}$ production } & \multirow{2}{*}{$\begin{array}{l}\text { NBT } \\
\text { reduction } \ddagger \\
\text { Toxoplasma }\end{array}$} \\
\hline & PMA & Zymosan & \\
\hline & \multicolumn{2}{|c|}{$\mathrm{nmol} / \mathrm{mg} / \mathrm{min}$} & $\%$ cells $N B T+$ \\
\hline \multicolumn{4}{|l|}{ Adult $\mathbf{M} \phi$} \\
\hline Control & $1.14 \pm 0.26$ & $0.48 \pm 0.13$ & $<4 \%$ \\
\hline Adult ConA sup & $1.29 \pm 0.39$ & $0.44 \pm 0.13$ & $<4 \%$ \\
\hline \multicolumn{4}{|l|}{ Placental $\mathbf{M} \phi$} \\
\hline Control & $1.87 \pm 0.38$ & $1.11 \pm 0.17$ & $<4 \%$ \\
\hline Adult ConA sup & $1.79 \pm 0.35$ & $1.19 \pm 0.31$ & $<4 \%$ \\
\hline
\end{tabular}

\footnotetext{
* M $\phi$ were cultured and exposed to adult ConA sups as described for Fig. 3. Then, monolayers were washed and overlayed with Krebs-Ringer's phosphate buffer (pH 7.4) containing $5.5 \mathrm{mM}$ glucose, $75 \mu \mathrm{M}$ ferricytochrome $C$, and PMA $(1.6 \mu \mathrm{g} / \mathrm{ml})$ or opsonized zymosan $(4 \mu \mathrm{g} / \mathrm{ml})$ in optimal concentrations. SOD $(50 \mu \mathrm{g} / \mathrm{ml})$ was added to control wells. After $90 \mathrm{~min}$, supernatants were aspirated and assayed for SOD-inhibitable reduction of ferricytochrome $C$. Results are the mean \pm SE for six (adult $\mathbf{M} \phi$ ) and three (placental $\mathbf{M} \phi$ ) experiments. Control and adult ConA sup-exposed monolayers had comparable protein content. Under these conditions, freshly isolated adult monocytes released $2.60 \pm 0.23$ and $2.17 \pm 0.01 \mathrm{nmol} \mathrm{O}_{2}^{\top} \mathrm{mg} / \mathrm{min}$ in response to PMA and zymosan, respectively.

¥ Monolayers were infected as described in Fig. 1 in the presence of $0.2 \mathrm{mg}$ NBT for $1 \mathrm{~h}$. Results are the mean \pm SE percentage of $M \phi$-containing Toxoplasma stained with formazan for three experiments. Under these conditions $\mathbf{9 4 . 0 \pm 3 . 0}$ and $89.5 \pm 4.5 \%$ of freshly isolated monocytes that ingested zymosan or Toxoplasma, respectively, reduced NBT around the particle.
}

to adult ConA sups $(16.0 \pm 3.7 \%)$ than in controls $(6.5 \pm 2.5 \%, n$ $=4 ; P<0.1,>0.05)$.

\section{Discussion}

Anti-toxoplasma activity and activation of newborn and adult $M \phi$. We found that the anti-Toxoplasma activity of newborn monocytes and $\mathbf{M} \phi$ was comparable with that of adult cells, and that both adult and newborn $\mathbf{M} \phi$ developed enhanced antiToxoplasma activity after exposure to adult ConA sups. Our results with adult $\mathrm{M} \phi$ and adult ConA sups are comparable with those reported previously $(9,15,21,22,29)$.

In contrast, cord blood ConA sups were significantly less effective than adult ConA sups at enhancing adult $\mathbf{M} \phi$ antiToxoplasma activity, and failed to enhance newborn $\mathbf{M} \phi$ antiToxoplasma activity. Further, supernatants of ConA-stimulated peripheral blood MC from 2-5-d old newborns did not enhance adult or newborn $\mathbf{M} \phi$ anti-Toxoplasma activity. Thus, both generation of and response to MAF were impaired in newborn cells.

In contrast to MAF generation, thymidine uptake, an index of cell replication, by ConA-stimulated cord blood MC was comparable with that by adult blood MC. Others have observed decreased generation of lymphokines by newborn blood MC compared with adult blood MC despite comparable thymidine uptake. Newborn blood MC produce less $\mathbf{M} \phi$ migration inhibition factor $(33,34)$, lymphotoxin (35), and lymphocyte-derived chemotactic factor (LDCF, 36) than do adult blood MC. Bryson et al. (37) found that newborn blood MC produced less $\gamma$-IF than did adult blood MC, whereas Handzel et al. (38) did not. Production of leukocyte migration inhibition factor by newborn cells is not significantly less than by adult cells $(34,38,39)$.

Decreased production of MAF by cord blood MC did not appear to be due to excessive suppression. OKT4 antigen-positive cells were the major producer of MAF and $\gamma$-IF both in adult and cord blood MC preparations. Although others $(40,41)$ have found that newborn $T$ suppressor cells ( $T-\gamma$ or OKT8-positive) inhibit autologous or allogeneic lymphocyte response in vitro, we were unable to demonstrate such an effect on MAF production by cord blood MC. We did not find prostaglandin- or monocyte-mediated suppression of cord blood MC lymphokine production, nor did cord blood MC inhibit production of MAF by adult blood MC. Further, addition of adult adherent cells to cord blood nonadherent cells did not enhance supernatant anti-Toxoplasma activity. These results suggest that MAF-producing lymphocytes may be deficient in number or in MAFor interleukin 2- (42) producing capacity in cord blood.

Cord blood ConA sups were significantly less effective at inducing anti-Toxoplasma activity in newborn $\mathbf{M} \phi$ than in adult M $\phi$. Similarly, $(a)$ newborn natural killer (NK) cell activity against herpes simplex virus-infected targets is less consistently enhanced by $\alpha$-IF than is adult NK cell activity (43); (b) cells from newborns are less susceptible to the induction of antiviral activity by $\alpha$-IF and $\gamma$-IF than are adult cells (44); and (c) newborn LDCF is a less effective stimulus for migration of newborn 
than adult monocytes, whereas adult LDCF stimulates comparable migration of both (36). These results suggest that cord blood MC are relatively deficient in generation of lymphokines and that newborn cells are less sensitive to the effects of certain of these lymphokines.

We did not find differences between cells obtained following vaginal or Caesarian delivery either: $(a)$ in the effects of cord blood ConA sups on $\mathbf{M} \phi$, or $(b)$ in the response to adult or cord blood ConA sups by cord blood or placental $\mathbf{M} \phi$. This differs from results with $\mathbf{M} \phi$ release of endogenous pyrogen, which is greater (45), and granulocyte oxidative metabolic response (46) and lymphocyte-mediated cytotoxicity (46), both of which are lower, in cord blood from newborns delivered after labor than after Caesarian delivery without labor.

Partial characterization of MAF. Our results suggest that part or all of the MAF activity in our ConA supernatants was $\gamma$-IF or that MAF was dependent on $\gamma$-IF to activate M $\phi$ under our conditions. The activity was lost by dialysis overnight at $\mathrm{pH} 2$ but not at $\mathrm{pH} 7.4$ and by preincubation with anti- $\gamma$-IF but not anti- $\alpha$-IF (47). Control supernatants or supernatants of OKT4-depleted ConA-stimulated adult blood MC lacked macrophage-activating activity and had $<100$ units/ml of IF. Previous studies have yielded conflicting results regarding the nature of MAF $(21,30,48,49)$. However, an increasing body of data suggests that $\gamma$-IF may account for most if not all the MAF activity of similar lymphokine preparations in assays of $\mathbf{M} \phi$ activity against Toxoplasma $(50,51)$, other microbes (52-54), and tumor cells (55-57). Further, consistent with the report by Nathan et al. (51), we have found that exposure of adult $\mathbf{M} \phi$ and placental $\mathbf{M} \phi$ to recombinant $\gamma$-IF decreases survival and replication of Toxoplasma in these cells (unpublished observations). These data are consistent with a major role for $\gamma$-IF in mediating enhanced $\mathbf{M} \phi$ anti-Toxoplasma under our conditions.

Certain data suggest that factors other than $\gamma$-IF may play a role in $\mathbf{M} \phi$ activation under our conditions. The anti-Toxoplasma activity of fibroblasts and WISH cells was not affected by exposure to adult ConA sups under our conditions or those used by Jones and Byrne (30). However, it is possible that these cells lack the appropriate mechanisms for transducing antiToxoplasma but not antiviral activity. Using different conditions, other workers have found that Toxoplasma replication in human fibroblasts (58) or mouse L cells (28) was impaired by $\gamma$-IF or by lymphokines, respectively. The anti-Toxoplasma activity in our studies and those of Nathan et al. (51) did not correlate strongly with antiviral activity. In addition, Nathan et al. (51) found that recombinant $\gamma$-IF had more potent $\mathbf{M} \phi$-activating activity per unit of antiviral activity than did partially purified $\gamma$-IF or $\gamma$-IF-containing lymphocyte culture supernatants. They proposed that this discrepancy might be related to: $(a)$ the presence of inhibitory or costimulatory factors in lymphocyte supernatants and in certain preparations of partially purified $\gamma$-IF; and $(b)$ less potent MAF activity per unit of antiviral activity in natural $\gamma$-IF, which isglycosylated, than in recombinant $\gamma$-IF, which is not glycosylated. The second possibility was fa- vored by their data (51). Similarly, one might speculate that the more profound deficiency in activity of cord blood ConA sups with newborn $\mathbf{M} \phi$ compared with adult $\mathbf{M} \phi$ might be due to: (a) the presence of factors which specifically inhibit, or the absence of factors which specifically enhance newborn compared with adult $\mathbf{M} \phi$ anti-Toxoplasma activity; (b) differences in glycosylation of $\gamma$-IF in cord blood compared with adult blood ConA sups that decrease effectiveness with newborn $\mathrm{M} \phi$ relative to adult $\mathbf{M} \phi$.

Although low levels of endotoxin $(<0.07-0.10 \mathrm{ng} / \mathrm{ml})$ were present in some of our culture medium, these concentrations were much lower than $100 \mu \mathrm{g} / \mathrm{ml}$ of endotoxin, which Jones and Byrne (30) found to be a necessary cofactor for enhancement of resident mouse peritoneal $\mathbf{M} \phi$ activity against Toxoplasma by lymphocyte supernatants. Further, our results were comparable with cells cultured in medium lacking detectable endotoxin, in medium containing $\sim 0.1 \mathrm{ng} / \mathrm{ml}$ of endotoxin, and in medium to which polymyxin $B(5 \mu \mathrm{g} / \mathrm{ml}$; unpublished observations) was added to inhibit the effects of endotoxin (31). Thus, although very low (1-100 pg/ml) concentrations of endotoxin may effect the ability of human $\mathbf{M} \phi$ to generate oxygen radicals (32), it is unlikely that endotoxin was a necessary cofactor for the enhancement of $\mathbf{M} \phi$ anti-Toxoplasma activity by adult ConA sups.

Mechanisms for the enhanced anti-Toxoplasma activity of activated $M \phi$. The mechanism for the enhanced $\mathrm{M} \phi$ anti-Toxoplasma activity was not fully defined by our study. Our results suggest that enhanced generation of reactive oxygen intermediates was not the principal mechanism. $\mathrm{O}_{\overline{2}}$ production by PMA or zymosan stimulated $\mathbf{M} \phi$ was not increased in adult ConA sup-exposed cells. Nakagawara et al. (59) and others (28, 50, 60 ) found that exposure of adult human monocyte-derived $\mathrm{M} \phi$ to adult ConA sups did increase release of $\mathrm{H}_{2} \mathrm{O}_{2}$; however, in the studies of Nakagawara et al. (59), $\mathrm{O}_{\dot{2}}$ generation was only slightly increased under the same conditions. We have also found that exposure to adult ConA sups augments $\mathrm{M} \phi \mathrm{H}_{2} \mathrm{O}_{2}$ release to a greater extent than $\mathrm{O}_{\overline{2}}^{\overline{2}}$ release (unpublished observations). The reason for the difference in detection by these assays is unclear (59). However, Toxoplasma ingestion failed to trigger detectable NBT reduction and oxygen metabolite scavengers did not reverse the anti-Toxoplasma activity of $\mathbf{M} \phi$ exposed to adult ConA sups. Thus, it appears unlikely that reactive oxygen metabolites mediated the enhanced $\mathrm{M} \phi$ anti-Toxoplasma activity. Further, phagolysosome fusion in adult ConA sup-exposed $\mathrm{M} \phi$ was not significantly $(P>0.05,<0.1)$ greater than in controls. We $(9,10)$ and others $(28,30)$ have previously concluded that the oxidative burst and lysosomal fusion are not required for M $\phi$ anti-Toxoplasma activity but may facilitate killing or inhibition of Toxoplasma by mononuclear phagocytes. This conclusion is supported by the observation that the anti-Toxoplasma activity of $\mathbf{M} \phi$ activated under the conditions described by Murray et al. (28) and Nathan et al. (51), which reduced NBT during ingestion of Toxoplasma and generated increased amounts of $\mathrm{H}_{2} \mathrm{O}_{2}$ in response to PMA, was somewhat greater than that of M $\phi$ activated under our conditions. It is possible that other 
mechanisms such as vacuolar acidification or entry of small cytoplasmic proteins without phagolysosome fusion (28) may in part mediate the anti-Toxoplasma effects of lymphokineexposed $\mathbf{M} \phi$. Since Toxoplasma, like viruses, is an obligate intracellular pathogen, it is also possible that the decreased survival and replication is due to interference with the as yet imprecisely defined metabolic support, which is normally provided by the cell to the parasite.

It is not possible to determine from our in vitro studies the relative role which monocytes, macrophages, and lymphokineinduced macrophage activation play in control of Toxoplasma infection in vivo. It is possible that these findings may relate to the increased severity of infection with Toxoplasma and other intracellular pathogens in human fetuses and newborns. Although the anti-Toxoplasma activity of newborn blood monocytes was comparable with that of adult blood monocytes, these cells are few in number compared with tissue $\mathbf{M} \phi$ and probably play a role only in limiting the initial dissemination of parasites $(10,15)$. Ultimate control of infection is probably dependent both on development of $\mathbf{M} \phi$ activation and specific antibody (3). Decreased generation of MAF by fetal lymphocytes and relatively decreased responsiveness to newborn MAF by placental M $\phi$ may allow unchecked replication of Toxoplasma in this organ. Unchecked replication of Toxoplasma in the placenta would contribute to subsequent spread of infection to the fetus, which occurs in $\sim 65 \%$ of pregnancies in which maternal Toxoplasma infection is acquired in the third trimester (1). Similarly, replication in the newborn's tissue macrophages and constitutive cells may be greater than in adults, leading to the greater incidence of significant tissue damage in newborns than in adults. Since disease in newborns is more severe when acquired early in utero it is possible that more severe deficits in macrophages activation or deficits in monocyte function would be found if similar assays were performed using cells from fetuses early in gestation. Interestingly, Toxoplasma infection does not appear to produce more severe infection in the pregnant than in the nonpregnant patient $(1,2)$, and the MAF activity of ConAstimulated blood MC from second and third trimester pregnant women was comparable with that from other adults (unpublished observations). Furthermore, decreased production of and response to $\gamma$-IF might also contribute to the newborn's greater susceptibility to infection with viruses such as herpes simplex and cytomegalovirus, susceptibility which may be mediated at least in part by M $\phi$ and NK cells and be modulated by IF (43, 61-64). Since newborn M $\phi$ do respond to MAF ( $\gamma$-IF) from adult cells, enhancement of these antimicrobial functions in newborns by exogenous IF or other immunomodulators may be possible.

\section{Acknowledgments}

We thank Drs. Jack Remington, Arnold Smith, Richard Locksley, Seymour Klebanoff, and Richard Root for their encouragement and advice; Dr. Joel Meyers for assistance with the interferon assays; Dr. Marlyn Langford for the antiserum to $\gamma$-IF; Dr. C. Sevastopoulos, Genentech
Inc., for the recombinant $\gamma$-IF; and Dr. Henry Murray for a helpful suggestion. We thank Judith Westall, William M. Weaver, and Alice Yasutake for technical assistance; and Kae Pierce for secretarial assistance.

This study was supported in part by grant HD/AI 18184 from the National Institutes of Health, grant 6-285 from the March of Dimes Birth Defects Foundation, and grant R-336-83 from United Cerebral Palsy.

\section{References}

1. Remington, J. S., and G. Desmonts. 1983. Toxoplasmosis. In Infectious Diseases of the Fetus and Newborn Infant. J. S. Remington and J. O. Klein, editors. W. B. Saunders Co., Philadelphia. Second ed. 144-263.

2. Wilson, C. B. 1982. Toxoplasmosis. In Gynecology and Obstetrics. J. W. Sciarra, editor. Harper and Row, Philadelphia. 1-6.

3. Remington, J. S., and J. L. Krahenbuhl. 1982. Immunology of Toxoplasma gondii. In Immunology of Human Infection. A. J. Nahmias and R. J. O'Reilly, editors. Plenum Publishing Co., New York. II:327371.

4. Murray, H. W. 1983. How protozoa evade intracellular killing. Ann. Intern. Med. 98:1016-1018.

5. Langford, M. P., D. A. Weigent, J. A. Georgiades, H. M. Johnson, and G. J. Stanton. 1981. Antibody to staphylococcal enterotoxin A-induced human immune interferon (IFN- $\gamma$ ). J. Immunol. 126:16201623.

6. Wilson, C. B., and J. S. Remington. 1979. Effects of monocytes from human neonates on lymphocyte transformation. Clin. Exp. Immunol. 36:511-520.

7. Gardner, I. D., and J. S. Remington. 1978. Aging and the immune response. II. Lymphocyte responsiveness and macrophage activation in Toxoplasma gondii infected mice. J. Immunol. 120:944-949.

8. Koski, I. R., D. G. Poplack, and R. M. Blaese. 1976. A nonspecific esterase strain for the identification of monocytes and macrophages. In In vitro Methods in Cell Mediated and Tumor Immunity. B. R. Bloom and J. R. David, editors. Academic Press, New York. 359-362.

9. Wilson, C. B., V. Tsai, and J. S. Remington. 1980. Failure to trigger the oxidative metabolic burst by normal macrophages. J. Exp. Med. 151:328-346.

10. Locksley, R. M., C. B. Wilson, and S. J. Klebanoff. 1982. Role for endogenous and acquired peroxidase in the toxoplasmacidal activity of murine and human mononuclear phagocytes. J. Clin. Invest. 69:10991111.

11. Wilson, C. B., J. E. Haas, and W. M. Weaver. 1983. Isolation, purification and characteristics of mononuclear phagocytes from human placentas. J. Immunol. Methods. 56:305-317.

12. Nacy, C. A., E. J. Leonard, and M. S. Meltzer. 1981. Macrophages in resistance to rickettsial infections: characterization of lymphokines that induce rickettsiacidal activity in macrophages. J. Immunol. 126:204209.

13. Henry, C. 1980. Cell separation. Adherence Nylon Wool. In Selected Methods in Cellular Immunology. B. B. Miskel and S. M. Shiigi, editors. W. H. Freeman and Co., San Francisco. 182-185.

14. McLeod, R., and J. S. Remington. 1979. A method to evaluate the capacity of monocytes and macrophages to inhibit multiplication of an intracellular pathogen. J. Immunol. Methods. 27:19-29.

15. Wilson, C. B., and J. S. Remington. 1979. Activity of human blood leukocytes against Toxoplasma gondii. J. Infect. Dis. 6:890-895.

16. Dulley, J. R., and P. A. Grieve. 1975. A simple technique for eliminating interference by detergents in the Lowry method of protein determination. Anal. Biochem. 64:136-141. 
17. Wilson, C. B., J. Bohnsack, and W. M. Weaver. 1982. Effects of muramyl dipeptide on superoxide anion release and on anti-microbial activity of human macrophages. Clin. Exp. Immunol. 49:371-376.

18. Goren, M. B., C. L. Swendsen, and J. Henson. 1980. Factors modifying the fusion of phagosomes and lysosomes: art, fact and fancy. In Mononuclear Phagocytes. Functional Aspects. Martinus Nijhoff Publishers. The Hague. 999-1038.

19. Meyers, J. D., R. W. McGuffin, P. E. Neiman, J. W. Singer, and E. D. Thomas. 1980. Toxicity and efficacy of human leukocyte interferon for treatment of cytomegalovirus pneumonia after marrow transplantation. J. Infect. Dis. 141:555-562.

20. Snedecor, G. W., and W. G. Cochran. 1969. Statistical Methods. Iowa State University Press, Ames. Sixth ed. 59-116.

21. Borges, J. S., and W. D. Johnson, Jr. 1975. Inhibition of multiplication of Toxoplasma gondii by human monocytes exposed to T-lymphocyte products. J. Exp. Med. 141:483-496.

22. Anderson, S. E., S. Bautista, and J. S. Remington. 1976. Induction of resistance to Toxoplasma gondii in human macrophages by soluble lymphocyte products. J. Immunol. 117:381-387.

23. Goodwin, J. S., A. D. Bankhurst, and R. P. Messner. 1977. Suppression of human T-cell mitogenesis by prostaglandin. J. Exp. Med. 146:1719-1734.

24. Possanza, G., M. C. Cohen, T. Yoshida, and S. Cohen. 1979. Human macrophage migration inhibition factor: evidence for subunit structure. Science (Lond.). 205:300-301.

25. Murray, H. W., C. W. Juangbhanich, C. F. Nathan, and Z. A. Cohn. 1979. Macrophage oxygen-dependent antimicrobial activity. II. The role of oxygen intermediates. J. Exp. Med. 150:950-964.

26. Murray, H. W., and Z. A. Cohn. 1980. Macrophage oxygendependent antimicrobial activity. III. Enhanced oxidative metabolism as an expression of macrophage activation. J. Exp. Med. 152:15961609.

27. Murray, H. W., C. F. Nathan, and Z. A. Cohn. 1980. Macrophage oxygen-dependent antimicrobial activity. IV. Role of endogenous scavengers of oxygen intermediates. J. Exp. Med. 152:1610-1624.

28. Murray, H. W., G. I. Byrne, C. D. Rothermel, and D. M. Cartelli. 1983. Lymphokines enhances oxygen-independent activity against intracellular pathogens. J. Exp. Med. 158:234-239.

29. Berman, J. D., and W. D. Johnson, Jr. 1978. Monocyte function in human neonates. Infect. Immun. 19:898-902.

30. Jones, T. C., and G. I. Byrne. 1980. Interactions of macrophages with intravacuolar bacteria and protozoa. In Mononuclear Phagocytes. Functional Aspects. R. vanFurth, editor. Martinus Nijhoff, The Hague. 1611-1629.

31. Weinberg, J. B., H. A. Chapman, Jr., and J. B. Hibbs, Jr. 1978. Characterization of the effects of endotoxin on macrophage tumor cell killing. J. Immunol. 121:72-80.

32. Pabst, M. J., H. B. Hedegaard, and R. B. Johnston. 1982. Cultured human monocytes require exposure to bacterial products to maintain an optimal oxygen radical response. J. Immunol. 128:123-128.

33. Stiehm, E. R., H. S. Winter, and Y. J. Bryson. 1979. Cellular (T cell) immunity in the human newborn. Pediatrics. 64:814-821.

34. Muller, M. R., S. Lazary, and W. H. Hitzig. 1976. Production of migration inhibitory factor and blast cell transformation by cord blood lymphocytes. Int. Archs. Allergy Appl. Immunol. 50:593-605.

35. Eife, R. F., G. Eife, C. S. August, W. L. Kuhre, and K. StaehrJohansen. 1974. Lymphotoxin production and blast cell transformation by cord blood lymphocytes: dissociated lymphocyte function in newborn infants. Cell. Immunol. 14:435-442.

36. Kretschmer, R. R., P. B. Stewardson, C. K. Papierniak, and
S. P. Gotoff. 1976. Chemotactic and bactericidal capacities of human newborn monocytes. J. ^mmunol. 117:1303-1307.

37. Bryson, Y. J., H. S. Winter, S. E. Gard, T. J. Fischer, and E. R. Stiehm. 1980. Deficiency of immune interferon production by leukocytes of normal newborns. Cell. Immunol. 55:191-200.

38. Handzel, Z. T., S. Levin, Z. Dolphin, M. Schlesinger, T. Hahn, Y. Altman, B. Schechter, A. Shneyour, and N. Trainin. 1980. Immune competence of newborn lymphocytes. Pediatrics. 65:491-496.

39. Hahn, T., S. Levin, and Z. T. Handzel. 1976. Leucocyte migration factor (LIF) production by lymphocytes of normal children, newborns, and children with immune deficiency. Clin. Exp. Immunol. 24:448454.

40. Hayward, A. R., and D. Merrill. 1981. Requirement for OKT8 ${ }^{+}$ suppressor cell proliferation for suppression by human newborn $T$ cells. Clin. Exp. Immunol. 45:468-474.

41. Rodriguez, M. A., A. D. Bankhurst, J. L. Ceuppens, and R. C. Williams, Jr. 1981. Characterization of the suppressor cell activity in human cord blood lymphocytes. J. Clin. Invest. 68:1577-1585.

42. Kasahara, T., J. J. Hooks, S. F. Dougherty, and J. J. Oppenheim. 1982. Interleukin 2-mediated immune interferon (IFN- $\gamma$ ) production by human T cells and T cell subsets. J. Immunol. 130:1784-1787.

43. Kohl, S., J. J. Frazier, S. B. Greenberg, L. K. Pickering, and L. Loo. 1981. Interferon induction of natural killer cytoxicity in human neonates. J. Pediatr. 98:379-384.

44. Thorley-Lawson, D. A. 1981 . The transformation of adult but not newborn human lymphocytes by Epstein Barr virus and phytohemagglutinin is inhibited by interferon: the early suppression by $\mathrm{T}$ cells or Epstein Barr infection is mediated by interferon. J. Immunol. 126:829833.

45. Dinarello, C. S., M. Shparber, E. F. Kent, Jr., and S. M. Wolff. 1981. Production of leukocytic pyrogen from phagocytes of neonates. J. Infect. Dis. 144:337-343.

46. Frazier, J. P., T. G. Cleary, L. K. Pickering, S. Kohl, and P. J. Ross. 1982. Leukocyte function in healthy neonates following vaginal and cesarean section deliveries. J. Pediatr. 101:269-272.

47. Epstein, L. B. 1979. The comparative biology of immune and classical interferons. In Biology of the Lymphokines. S. Cohen, E. Pick, and J. J. Oppenheim, editors. Academic Press, New York. 443-514.

48. Chinchilla, M., and J. K. Frenkel. 1978. Mediation of immunity to intracellular infection (Toxoplasma and Besnoitia) within somatic cells. Infect. Immun. 19:999-1012.

49. Ahronheim, G. A. 1979. Toxoplasma gondii: human interferon studies by plaque assay. Proc. Soc. Exp. Biol. Med. 161:522-526.

50. Shirahata, T., and K. Shimizu. 1979. Some physiocochemical characteristics of an immune lymphocyte product which inhibits the multiplication of Toxoplasma within mouse macrophages. Microbiol. Immunol. 23:17-30.

51. Nathan, C. F., H. W. Murray, M. E. Wiebe, and B. Y. Rubin. 1983. Identification of interferon- $\gamma$ as the lymphokine that activates human macrophage oxidative metabolism and antimicrobial activity. J. Exp. Med. 158:670-689.

52. Turco, J., and H. H. Winkler. 1983. Inhibition of the growth of Rickettsia Prowazekii in cultured fibroblasts by lymphokines. J. Exp. Med. 157:974-986.

53. Wisseman, C. L., Jr., and A. Waddell. 1983. Interferon like factors from antigen- and mitogen-stimulated human leukocytes with antirickettsial and cytolytic actions on Rickettsia Prowazekii. J. Exp. Med. 157:1780-1793.

54. Murray, H. W., B. Y. Rubin, and C. D. Rothermel. 1983. Killing 
of intracellular Leishmania donovani by lymphokine-stimulated human mononuclear phagocytes: evidence that interferon- $\gamma$ is the activating lymphokine. J. Clin. Invest. 72:1506-1510.

55. Schreiber, R. D., J. L. Pace, S. W. Russell, A. Altman, and D. H. Katz. 1983. Macrophage-activating factor produced by a $T$ cell hybridoma: physiochemical and biosynthetic resemblance to $\gamma$-interferon. J. Immunol. 131:826-832.

56. Meltzer, M. S., W. R. Benjamin, and J. J. Farrar. 1982. Macrophage activation for tumor cytotoxicity: induction of macrophage tumoricidal activity by lymphokines from EL-4, a continuous $\mathrm{T}$ cell line. J. Immunol. 129:2802-2807.

57. Kleinschmidt, W. J., and R. M. Schultz. 1982. Similarities of murine gamma interferon and the lymphokine that renders macrophages cytotoxic. J. Interferon Res. 2:291-299.

58. Pfefferkorn, E. R., and P. M. Guyre. 1983. Recombinant human gamma interferon blocks the growth of Toxoplasma gondii in cultured human fibroblasts. Fed. Proc. 42:964.

59. Nakagawara, A., N. M. DeSantis, N. Noguiera, and C. F. Nathan.
1982. Lymphokines enhance the capacity of human monocytes to secrete reactive oxygen intermediates. J. Clin. Invest. 70:1042-1048.

60. Murray, H. W., and D. M. Cartelli. 1983. Killing of intracellular Leishmania donovani by human mononuclear phagocytes. J. Clin. Invest. 72:32-44.

61. Hirsch, M. S., B. Zisma, and A. C. Allison. 1970. Macrophages and age-dependent resistance to herpes simplex virus in mice. J. Immunol. 104:1160-1165.

62. Drew, W. L., L. Mintz, R. Hoo, and T. N. Finley. 1979. Growth of herpes simplex and cytomegalovirus in cultured human alveolar macrophages. Am. Rev. Respir. Dis. 119:287-291.

63. Lopez, C., D. Kirkpatrick, P. A. Fitzgerald, C. Y. Ching, R. N. Pahwa, R. A. Good, and E. M. Smithwick. 1982. Studies of the cell lineage of the effector cells that spontaneously lyse HSV-1 infected fibroblasts (NK(HSV-1)). J. Immunol. 129:824-828.

64. Jordan, M. C., and V. L. Mar. 1982. Spontaneous activation of latent cytomegalovirus from murine spleen explants. J. Clin. Invest. 70:762-768. 